\title{
Papers
}

\section{Impact of supplementing newborn infants with vitamin A on early infant mortality: community based randomised trial in southern India}

Lakshmi Rahmathullah, James M Tielsch, R D Thulasiraj, Joanne Katz, Christian Coles, Sheela Devi, Rajeesh John, Karthik Prakash, A V Sadanand, N Edwin, C Kamaraj

\begin{abstract}
Objective To assess the impact of supplementing newborn infants with vitamin A on mortality at age 6 months.

Design Community based, randomised, double blind, placebo controlled trial.

Setting Two rural districts of Tamil Nadu, southern India.

Participants 11619 newborn infants allocated 24000 IU oral vitamin A or placebo on days 1 and 2 after delivery.

Main outcome measure Primary outcome measure was mortality at age 6 months.

Results Infants in the vitamin A group had a 22\% reduction in total mortality $(95 \%$ confidence interval $4 \%$ to $37 \%$ ) compared with those in the placebo group. Vitamin A had an impact on mortality between two weeks and three months after treatment, with no additional impact after three months.

Conclusion Supplementing newborn infants with vitamin A can significantly reduce early infant mortality.
\end{abstract}

\section{Introduction}

Ocular signs of vitamin A deficiency are associated with increased mortality among children aged 6 months or older. ${ }^{1}$ Supplementation with vitamin A can significantly reduce total mortality. ${ }^{2-8}$ The impact of supplementation is only clear in children aged 6 months or older. It was assumed that breast feeding protected infants from vitamin A deficiency and that clinical signs of xerophthalmia appeared only after the onset of weaning or incorrect bottle feeding. ${ }^{1}$ Recent evidence challenges these assumptions. Infants are born with low stores of vitamin A and depend on feeding to build body stores. ${ }^{9-11}$ If the mother's breast milk has a low concentration of vitamin A, as found in many women in developing countries, the infant will be unable to meet daily requirements and increase body reserves. ${ }^{12}$

Supplementation of women post partum can improve the concentration of vitamin A in their blood and breast milk, but data on the impact of supplementing infants early with vitamin A on survival are conflicting. ${ }^{13}{ }^{14}$ A study in Nepal found no difference in mortality between infants supplemented with vitamin A or placebo before 6 months of age (relative risk 1.11, $95 \%$ confidence interval 0.86 to 1.42$).{ }^{15} \mathrm{~A}$ trial conducted in three countries also found no impact on mortality in the first six months from supplementing with vitamin A both mothers post partum and their infants at all three visits for diphtheria, tetanus, and pertussis immunisations. ${ }^{16}$ Another study in Nepal found no effect on early infant mortality from supplementing women with vitamin $\mathrm{A}$ or $\beta$ carotene before and during pregnancy. ${ }^{17}$ In contrast, supplementing infants with $50000 \mathrm{IU}$ of vitamin A within 24 hours of birth was safe and associated with a $64 \%$ reduction in infant mortality ${ }^{18}$ We aimed to determine the impact of supplementing infants with vitamin A within 48 hours of delivery on early infant mortality.

\section{Methods}

Our study (the vitamin A supplementation in newborns (VASIN)) was a randomised, placebo controlled, community based trial conducted between June 1998 and March 2001 in two rural districts of Tamil Nadu, southern India.

\section{Eligibility and randomisation}

Liveborn infants that resulted from all pregnancies within participating villages were eligible for participation. Pregnant women were identified for recruitment from a variety of sources. Project staff explained the study to them and attempted to recruit them before delivery. Verbal informed consent was obtained at the time of recruitment. Baseline information on personal and socioeconomic characteristics was collected by interview. Pregnant women in this area of India traditionally move in with their parents for delivery and for up to six months after delivery. Eligibility was therefore determined by where the woman delivered her child.

Randomisation was at the individual level, stratified by geographical area in blocks of four. Because births were likely in a variety of locations, randomisation was conducted at the time of recruitment. Exclusions after randomisation were stillbirths, miscarriages, delivery more than $20 \mathrm{~km}$ outside the study area, and infants
Aravind Centre for Women, Children and Community Health, Madurai, Tamil Nadu, India Lakshmi Rahmathullah director

Department of International Health, Bloomberg School of Public Health, Johns

Hopkins University, Baltimore, MD 21205-2103, USA

James M Tielsch professor

Joanne Katz

professor

Christian Coles assistant research professor

Lions-Aravind Institute for

Community

Ophthalmology,

Madurai, Tamil

Nadu, India

R D Thulasiraj

executive director

Sheela Devi research coordinator

Rajeesh John

biostatistician

Karthik Prakash biostatistician

A V Sadanand faculty

continued over

bmj.com 2003;327:254

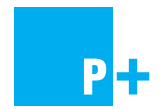

A table on cause specific mortality appears on bmj.com 
Department of Pediatrics, Madura Medical College, Madurai, Tamil

Nadu, India

$\mathrm{N}$ Edwin

professor

C Kamaraj

professor

Correspondence to: J M Tielsch jtielsch@jhsph.edu who died before our study team arrived. For twins, the first born received the assigned treatment and the second born the other treatment. For triplets, the first two born infants were handled as twins and the third born received the originally assigned treatment.

\section{Intervention and data collection}

The infants were randomly assigned to receive either $24000 \mathrm{IU}$ of vitamin A twice within a 24 hour interval, beginning within 48 hours of birth, or placebo. The treatment doses were in an edible oil solution packaged in identical gelatin capsules. Mothers were encouraged to breast feed their infant immediately after treatment to ensure consumption of the full dose. Each set of two capsules was packaged separately and labelled with the mother's identifying information. Investigators, study staff, and mothers were masked to the assigned treatment. Treatment codes were kept in a sealed envelope in a locked filing cabinet in Baltimore.

Table 1 Baseline characteristics of mothers and their families according to whether newborn infants received placebo or supplementation with vitamin A. Values are numbers (percentages) unless stated otherwise

\begin{tabular}{|c|c|c|c|}
\hline Characteristics & Placebo group $(n=5833)$ & Vitamin A group ( $n=5786$ ) & $P$ value \\
\hline \multicolumn{4}{|l|}{ Age of mother (years): } \\
\hline $15-19$ & $759(13.0)$ & $718(12.4)$ & \multirow{5}{*}{0.36} \\
\hline $20-24$ & $2878(49.3)$ & $2796(48.3)$ & \\
\hline $25-29$ & $1714(29.4)$ & $1775(30.7)$ & \\
\hline $30-34$ & $389(6.7)$ & $389(6.7)$ & \\
\hline$\geq 35$ & $93(1.6)$ & $108(1.9)$ & \\
\hline \multicolumn{4}{|c|}{ Years of education of mother: } \\
\hline 0 & $2534(43.4)$ & $2536(43.8)$ & \multirow{5}{*}{0.85} \\
\hline $1-3$ & $349(6.0)$ & $344(6.0)$ & \\
\hline $4-6$ & 1354 (23.2) & $1331(23.0)$ & \\
\hline $7-9$ & $978(16.8)$ & 935 (16.2) & \\
\hline$\geq 10$ & $618(10.6)$ & $640(11.1)$ & \\
\hline \multicolumn{4}{|c|}{ Occupation of head of household: } \\
\hline Farmer-landowner & $2247(38.5)$ & 2249 (38.9) & \multirow{6}{*}{$<0.001$} \\
\hline Farmer labourer & $495(8.5)$ & $452(7.8)$ & \\
\hline Day labourer & $2338(40.1)$ & $2334(40.3)$ & \\
\hline Government worker & $152(2.6)$ & $124(2.1)$ & \\
\hline Private office worker & $305(5.2)$ & $281(4.9)$ & \\
\hline Other & $296(5.1)$ & $346(6.0)$ & \\
\hline \multicolumn{4}{|l|}{ Type of roof on home: } \\
\hline Thatch & $1854(31.8)$ & $1795(31.0)$ & \multirow{4}{*}{0.20} \\
\hline Tile & $2829(48.5)$ & $2834(49.0)$ & \\
\hline Concrete & $1116(19.1)$ & $1137(19.7)$ & \\
\hline Other & $34(0.6)$ & $20(0.4)$ & \\
\hline \multicolumn{4}{|l|}{ Electricity in home: } \\
\hline Yes & $3320(56.9)$ & 3349 (57.9) & \multirow{2}{*}{0.29} \\
\hline No & $2513(43.1)$ & $2437(42.1)$ & \\
\hline \multicolumn{4}{|c|}{ Radio or television in home: } \\
\hline Neither & $3324(57.0)$ & $3282(56.7)$ & \multirow{4}{*}{0.17} \\
\hline Radio only & $1440(24.7)$ & $1443(24.9)$ & \\
\hline Television only & $541(9.3)$ & $486(8.4)$ & \\
\hline Both & $528(9.1)$ & $575(9.9)$ & \\
\hline \multicolumn{4}{|l|}{ Land ownership: } \\
\hline Yes & $2892(49.6)$ & $2863(49.5)$ & \multirow{2}{*}{0.92} \\
\hline No & $2941(50.4)$ & $2923(50.5)$ & \\
\hline \multicolumn{4}{|l|}{ Cattle ownership: } \\
\hline Yes & 1555 (26.6) & $1643(28.4)$ & \multirow{2}{*}{0.03} \\
\hline No & $4283(73.4)$ & $4143(71.6)$ & \\
\hline \multicolumn{4}{|l|}{ Caste: } \\
\hline Forward & $6(0.1)$ & $7(0.1)$ & \multirow{5}{*}{0.69} \\
\hline Backward & $2291(39.3)$ & $2271(39.3)$ & \\
\hline Most backward & $2356(40.4)$ & $2333(40.3)$ & \\
\hline Scheduled & $1151(19.7)$ & $1134(19.6)$ & \\
\hline Others & $29(0.5)$ & $41(0.7)$ & \\
\hline
\end{tabular}

Village based staff notified their supervisor when a birth had occurred. The supervisor travelled to the site of the delivery to provide the assigned treatment, weigh the infant, and collect information on the delivery. Supervisors had a target to begin treatment within 48 hours of birth or as soon as possible if this was not achievable. Weight was measured with an electronic infant weighing scale (Seca Model 727; Seca, Columbia, MD).

The day after the first dose, the supervisor revisited the household to collect any comments on treatment and to provide the second dose. In the case of adverse events, a report was completed and the child visited daily for seven days.

Project staff visited the household every two weeks to assess the vital status of the child and any morbidity. Infants were followed until 6 months of age. Before discharge the infants had anthropometric measurements taken and were given a $100000 \mathrm{IU}$ dose of vitamin A. We considered as censored those infants aged less than 6 months who were being followed at the end of March 2001.

\section{Measurement of outcomes}

The primary outcome was mortality within the first six months of life. Infant deaths were ascertained during the vital status and morbidity assessments. Cause of death was determined from an independent review of verbal autopsy information from family members by two paediatricians. Disagreements were resolved by consensus with a third paediatrician.

\section{Sample size and statistical analysis}

Our study was designed to detect a minimum reduction in infant mortality at age 6 months of 30\%; given an expected infant mortality at 6 months of age of 52.5 per 1000 live births, $80 \%$ power, a $5 \%$ two sided type I error, and $10 \%$ loss to follow up. We required 3000 live births per group. Unknown was the number of deaths that would occur before infants were enrolled into our study. An independent data and safety monitoring board, which met twice to review our data, advised us to increase the recruitment period to be able to detect a $20 \%$ reduction among enrolled infants because the mortality of enrolled infants was lower than expected due to early deaths. We therefore required 4500 live births per group.

Statistical analysis was performed with SAS. Treatment groups were compared on baseline household, maternal, and infant characteristics for all deliveries and for liveborn infants who were enrolled. We used three approaches for the primary analysis of treatment effect on mortality. Firstly, we estimated the incidence density of mortality with person time as the denominator. This permitted use of all data, including infants who were censored at the time follow up was completed. Secondly, we estimated the infant mortality at age 6 months, with live births as the denominator. We included in this analysis only infants who were followed to 6 months. Thirdly, we performed a survival analysis. Cox proportional hazard models were used to adjust for potential confounding and to model potential effect modification. All analyses were based on intention to treat. 


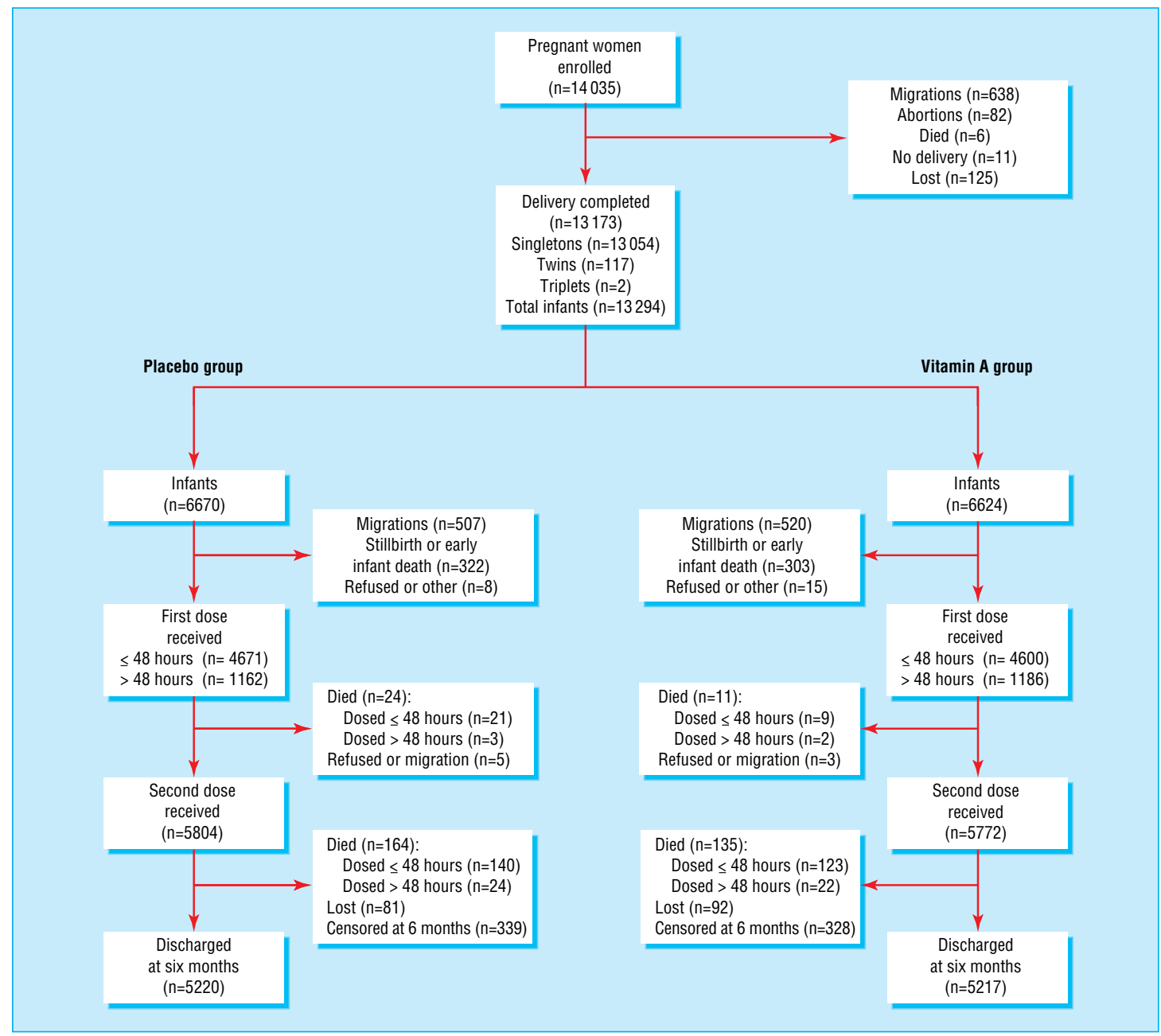

Fig 1 Flow of participants through trial

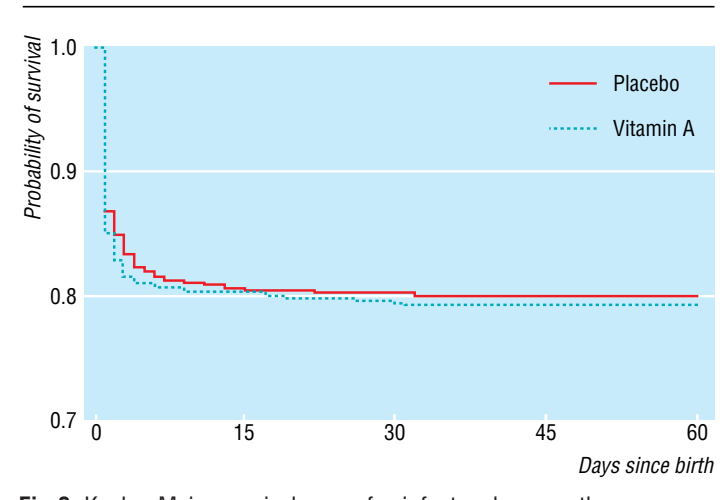

Fig 2 Kaplan-Meier survival curve for infants whose mothers were randomised but who were not enrolled and received supplementation with vitamin $\mathrm{A}$. Log rank test: $\chi^{2}=0.12, \mathrm{P}=0.73$, hazard ratio 1.05 (0.80 to 1.37$)$

\section{Results}

We recruited 14035 pregnant women; 862 of these did not deliver within the study area (fig 1). Overall, 13294 infants were born; $6670(50.2 \%)$ were allocated placebo and $6624(49.8 \%)$ were allocated vitamin A. The parents of 23 infants refused to participate after delivery, families of 1027 infants moved out of the area, and 625 were stillborn or died before our teams arrived.
This left 11619 liveborn infants enrolled and followed; $5833(50.2 \%)$ in the placebo group and $5786(49.8 \%)$ in the vitamin A group.

Baseline characteristics of the families, mothers, and infants were similar between the treatment groups (tables 1 to 3, fig 2). This applied to all deliveries and to those infants who were enrolled. About $13 \%$ of mothers were aged under 20 at the time of the pregnancy. Over $40 \%$ of mothers had no formal education. About $8 \%$ reported a history of miscarriage, and $4 \%$ reported a

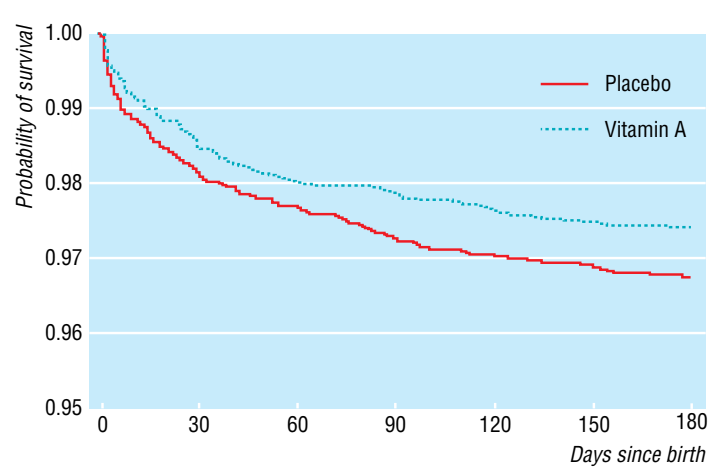

Fig 3 Kaplan-Meier survival curve for enrolled infants. Log rank test: $\chi^{2}=5.12, P=0.02$, hazard ratio 0.78 (0.63 to 0.97 ) 
Table 2 Mothers' reproductive history at baseline according to whether newborn infants received placebo or supplementation with vitamin A. Values are numbers (percentages) unless stated otherwise

\begin{tabular}{|c|c|c|c|}
\hline Characteristics & Placebo group $(\mathrm{n}=5833$ ) & Vitamin A group ( $n=5786$ ) & $P$ value \\
\hline \multicolumn{4}{|l|}{ No of pregnancies: } \\
\hline 1 & 1909 (32.7) & $1849(32.0)$ & \multirow{5}{*}{0.30} \\
\hline $2-3$ & $2968(50.9)$ & 2999 (51.8) & \\
\hline $4-5$ & $769(13.2)$ & $746(12.9)$ & \\
\hline 6-8 & $165(2.8)$ & $180(3.1)$ & \\
\hline$\geq 9$ & $22(0.4)$ & $12(0.2)$ & \\
\hline \multicolumn{4}{|l|}{ Previous miscarriage: } \\
\hline Yes & $454(7.8)$ & $461(8.0)$ & \multirow{2}{*}{0.71} \\
\hline No & $5379(92.2)$ & $5325(92.0)$ & \\
\hline \multicolumn{4}{|l|}{ Previous stillbirth: } \\
\hline Yes & $243(4.2)$ & $220(3.8)$ & \multirow{2}{*}{0.32} \\
\hline No & $5590(95.8)$ & 5566 (96.2) & \\
\hline \multicolumn{4}{|l|}{ Night blindness in index pregnancy: } \\
\hline Yes & $322(5.5)$ & $352(6.1)$ & \multirow{2}{*}{0.26} \\
\hline No & 5511 (94.5) & 5434 (93.9) & \\
\hline Mean (SD) No of infants born alive & $1.20(1.30)$ & $1.21(1.27)$ & 0.64 \\
\hline Mean (SD) No of infants born dead & $0.05(0.25)$ & $0.04(0.23)$ & 0.04 \\
\hline Mean (SD) No of miscarriages & $0.10(0.38)$ & $0.10(0.38)$ & 1.0 \\
\hline
\end{tabular}
Table 3 Details of deliveries according to whether newborn infants received placebo or
supplementation with vitamin A

\begin{tabular}{|c|c|c|c|}
\hline Characteristics & Placebo group $(n=5833)$ & Vitamin A group $(n=5786)$ & $P$ value \\
\hline \multicolumn{4}{|l|}{ Place of delivery: } \\
\hline Home & $2136(36.6)$ & $2176(37.6)$ & \multirow{5}{*}{0.15} \\
\hline Primary health centre & $260(4.5)$ & $250(4.3)$ & \\
\hline Hospital & $3147(54.0)$ & $3127(54.0)$ & \\
\hline Maternity home & $274(4.7)$ & $219(3.8)$ & \\
\hline Other & $16(0.3)$ & $14(0.2)$ & \\
\hline \multicolumn{4}{|l|}{ Birth attendant: } \\
\hline Physician & $2325(39.9)$ & $2351(40.6)$ & \multirow{5}{*}{0.26} \\
\hline Nurse & $1441(24.7)$ & $1327(22.9)$ & \\
\hline Trained midwife & $1023(17.5)$ & 1059 (18.3) & \\
\hline Untrained midwife & $821(14.1)$ & $824(14.2)$ & \\
\hline Other & $223(3.8)$ & $225(3.9)$ & \\
\hline \multicolumn{4}{|l|}{ Sex of infant: } \\
\hline Male & $3034(52.0)$ & $2934(50.8)$ & \multirow{2}{*}{0.16} \\
\hline Female & $2799(48.0)$ & $2852(49.2)$ & \\
\hline \multicolumn{4}{|l|}{ Birth weight $(g)^{\star}$ : } \\
\hline$<1500$ & $51(0.9)$ & $47(0.8)$ & \multirow{7}{*}{0.96} \\
\hline $1500-1999$ & $275(4.7)$ & $278(4.8)$ & \\
\hline $2000-2499$ & $1525(26.1)$ & $1495(25.8)$ & \\
\hline $2500-2749$ & $1485(25.5)$ & $1521(26.3)$ & \\
\hline $2750-2999$ & $1241(21.3)$ & $1229(21.2)$ & \\
\hline $3000-3499$ & $1062(18.3)$ & $1022(17.7)$ & \\
\hline$\geq 3500$ & $194(3.3)$ & $194(3.4)$ & \\
\hline \multicolumn{4}{|c|}{ Time breast feeding began after delivery: } \\
\hline Within 12 hours & $4784(82.0)$ & $4633(80.1)$ & \multirow{4}{*}{0.04} \\
\hline 12-24 hours & $748(12.8)$ & $832(14.4)$ & \\
\hline$>24$ hours & $286(4.9)$ & $310(5.4)$ & \\
\hline Not breast fed & $15(0.3)$ & $11(0.2)$ & \\
\hline \multicolumn{4}{|c|}{ Time between delivery and study visit: } \\
\hline$<6$ hours & $310(5.3)$ & $325(5.6)$ & \multirow{6}{*}{0.68} \\
\hline $6-12$ hours & $702(12.0)$ & $661(11.4)$ & \\
\hline$>12-24$ hours & $1705(29.2)$ & $1658(28.7)$ & \\
\hline$>24-48$ hours & $1954(33.5)$ & $1956(33.8)$ & \\
\hline$>48$ hours-7 days & $559(9.6)$ & $548(9.5)$ & \\
\hline$>7$ days & $603(10.3)$ & $638(11.0)$ & \\
\hline
\end{tabular}

previous stillbirth. Over $60 \%$ of births were attended by a physician or nurse, and around 20\% were attended by a trained midwife. Five to $6 \%$ of women reported a history of night blindness, a clinical symptom of vitamin A deficiency. The mean birth weights were $2675 \mathrm{~g}$ in the placebo group and $2673 \mathrm{~g}$ in the vitamin A group (31\% of infants weighed less than $2500 \mathrm{~g})$. Similar proportions of mothers in both groups began breast feeding within 12 hours of birth and reported feeding colostrum. Mortality of infants born alive but not enrolled was similar in both groups (fig 2). Eighty per cent of infants were first dosed within 48 hours of birth (median time to first dose, 25.5 hours in placebo group and 26.4 hours in vitamin A group).

Side effects were uncommon. Six cases occurred in the placebo group and three in the vitamin A group. Most of these were vomiting; there were no reports of bulging fontanelle.

Supplementing newborn infants with vitamin A was associated with a $22-23 \%$ reduction in mortality during the first six months of life (table 4 and fig 3). Similar estimates of relative risk were obtained with the incidence density analysis $(0.78,95 \%$ confidence interval 0.63 to 0.96$)$, infant mortality at 6 months $(0.77$, 0.62 to 0.96 ), and an estimate of the hazard ratio (hazard ratio $0.78,0.63$ to 0.97 ). No substantial change was observed in these estimates when adjusting for additional baseline variables (data not shown). The survival curves began to diverge at around 2 weeks of age and continued to separate until 3 months of age (fig 3 ). After 3 months the curves remained parallel, indicating no further treatment effect.

Little evidence was found for an effect modification by sex (table 4 , test for interaction, $\mathrm{P}=0.33$ ). The impact of vitamin A on survival was limited to infants who were treated before 14 days (table 5), although the strength of evidence for this interaction was low (test for interaction, $\mathrm{P}=0.68$ ). The effect was also limited to infants of low birth weight (table 6). In this group, vitamin A reduced mortality at 6 months by $37 \%$. In contrast, there was no effect of vitamin A on mortality among infants weighing $2500 \mathrm{~g}$ or more at birth (test for interaction, $\mathrm{P}=0.02$ ).

\section{Discussion}

Giving newborn infants two doses of 24000 IU of vitamin A within 48 hours of birth significantly reduced early infant mortality. Our results agree with those from a hospital based study in Indonesia, which reported a $64 \%$ reduction in infant mortality associated with giving newborn infants $50000 \mathrm{IU}$ of vitamin $A .{ }^{18}$ As in our results, the impact of vitamin A on survival was limited to the first three or four months of life. The greatest impact in the Indonesian study was among infants who weighed $2500 \mathrm{~g}$ or more at birth. In contrast, we found the greatest effect among infants of low birth weight.

The discrepancy with studies that supplemented infants later in the first six months suggests something unique about receiving a large dose of vitamin $\mathrm{A}$ shortly after birth. ${ }^{15-17}$ Although the underlying mechanism for this differential impact by age is unknown, two explanations are plausible. Humans are born with marginal reserves of vitamin A and depend on breast milk or other sources to meet their metabolic demands in the first few months of life. Premature infants have even lower reserves of vitamin $\mathrm{A}$, and correction of the deficiency has been shown to reduce the respiratory complications of preterm birth. ${ }^{19}$ A large bolus of vita- 


\section{What is already known on this topic}

Supplementation with a large dose of vitamin A reduces mortality among children aged 6 months to 5 years in many developing countries

The effect of supplementation on mortality in newborn infants under 6 months of age is unclear

Periodic treatment with vitamin A beyond the first month of life has no impact on mortality

\section{What this study adds}

Supplementing infants with vitamin A in the first few days after birth significantly reduced infant mortality

The greatest impact was observed between 2 weeks and 3 to 4 months of age

min A early in the neonatal period may provide a stimulus to rapid maturation of both gut and respiratory epithelium. This matured epithelium may be more resistant to invasion by pathogens or may clear such organisms more efficiently.

Another potential mechanism relates to the role of vitamin $\mathrm{A}$ in the development and maintenance of immunocompetence. Vitamin A deficiency causes alterations in $\mathrm{T}$ cell subsets, impaired phagocytic activity, and reduced antibody response to antigen challenge. ${ }^{20-22}$ Retinoic acid is an important regulator of gene expression and cell differentiation, and vitamin A deficiency can cause alterations in the balance of Th1 versus Th2 type cytokine response. ${ }^{23} 24$ However, these effects have been observed in animal models and humans after the newborn period.

Our study had limitations. The need to maintain control over delivery of the assigned treatment, and the variation in locations and time at which deliveries took place, resulted in a delay in arrival at the place of delivery. We therefore missed several children who were born alive and subsequently moved, whose parents refused participation, or who died before the arrival of our staff. Although there was no difference in survival between the treatment groups before enrolment, the delay prevented estimation of the effect of supplementation on total six month infant mortality.

We thank G Venkataswamy and P Namperumalswamy for their support, the members of the Data and Safety Monitoring Board, including the late V Ramalingaswamy (All India Institute of Medical Sciences, New Delhi), P S S Sundar Rao (Schieffelin Leprosy Research and Training Centre, Karigiri), S J M Jeyam (Institute for Child Health, Chennai), K Vijayaraghavan (National Institute of Nutrition, Hyderabad), and Vijaya Srinivasan (Gandhigram Institute of Rural Health and Family Welfare).

Contributors: LR, JT, RDT, and JK helped design the study. LR, JT, RDT, CC, SD, and AVS supervised the conduct of the study, JT, RDT, JK, RJ, and KP were involved in the analysis and interpretation of the data. LR, CC, NE, and CK were involved in the interpretation of the data. JK and KP designed the data management system. $\mathrm{NE}$ and $\mathrm{CK}$ reviewed the verbal autopsies and determined the cause of death for the study. All authors contributed to writing or editing the manuscript, or both.JT will act as guarantor for the paper.

Funding: This study received support from Cooperative Agreement No HRN-A-00-97-00015-00 between the Center for Human Nutrition (Bloomberg School of Public Health, Johns
Table 4 Relative risk of mortality in newborn infants receiving placebo or supplementation with vitamin A according to sex

\begin{tabular}{|c|c|c|c|c|}
\hline $\begin{array}{l}\text { Sex and treatment } \\
\text { group }\end{array}$ & Infant years & No of deaths & $\begin{array}{l}\text { Mortality } \\
\text { rate/1000 }\end{array}$ & Relative risk $(95 \% \mathrm{Cl})$ \\
\hline \multicolumn{5}{|l|}{ Total: } \\
\hline Placebo & 2719.1 & 188 & 69.1 & \multirow{2}{*}{0.78 (0.63 to 0.96$)$} \\
\hline Vitamin A & 2713.0 & 146 & 53.8 & \\
\hline \multicolumn{5}{|l|}{ Males: } \\
\hline Placebo & 1412.3 & 100 & 70.8 & \multirow{2}{*}{0.70 (0.52 to 0.94$)$} \\
\hline Vitamin A & 1378.2 & 68 & 49.3 & \\
\hline \multicolumn{5}{|l|}{ Females: } \\
\hline Placebo & 1306.7 & 88 & 67.3 & \multirow{2}{*}{0.87 (0.65 to 1.17$)$} \\
\hline Vitamin A & 1334.8 & 78 & 58.4 & \\
\hline
\end{tabular}

Table 5 Relative risk of mortality in newborn infants receiving placebo or supplementation with vitamin A according to time of dosing

\begin{tabular}{|c|c|c|c|c|}
\hline $\begin{array}{l}\text { Time of dosing and } \\
\text { treatment group }\end{array}$ & Infant years & No of deaths & $\begin{array}{l}\text { Mortality } \\
\text { rate/1000 }\end{array}$ & Relative risk (95\% Cl) \\
\hline \multicolumn{5}{|l|}{$\geq 48$ hours: } \\
\hline Placebo & 2176.7 & 161 & 74.0 & \multirow{2}{*}{0.77 (0.61 to 0.97$)$} \\
\hline Vitamin A & 2150.2 & 122 & 56.7 & \\
\hline \multicolumn{5}{|l|}{48 hours to $<7$ days: } \\
\hline $\begin{array}{l}\text { Placebo } \\
\end{array}$ & 260.7 & 12 & 46.0 & \multirow{2}{*}{0.83 (0.36 to 1.92$)$} \\
\hline Vitamin A & 261.4 & 10 & 38.3 & \\
\hline \multicolumn{5}{|l|}{7 days to $<14$ days: } \\
\hline Placebo & 149.6 & 9 & 60.2 & \multirow{2}{*}{0.80 (0.31 to 2.08$)$} \\
\hline Vitamin A & 165.4 & 8 & 48.4 & \\
\hline \multicolumn{5}{|l|}{$\geq 14$ days: } \\
\hline Placebo & 132.1 & 6 & 45.4 & \multirow{2}{*}{0.97 (0.38 to 2.48 ) } \\
\hline Vitamin A & 135.9 & 6 & 44.2 & \\
\hline
\end{tabular}

Table 6 Relative risk of mortality in newborn infants receiving placebo or supplementation with vitamin A according to birth weight

\begin{tabular}{|c|c|c|c|c|}
\hline $\begin{array}{l}\text { Birth weight and } \\
\text { treatment group }\end{array}$ & Infant years & $\begin{array}{l}\text { No of } \\
\text { deaths }\end{array}$ & Mortality rate/1000 & Relative risk $(95 \% \mathrm{CI})$ \\
\hline \multicolumn{5}{|l|}{$<2000 \mathrm{~g}:$} \\
\hline Placebo & 134.7 & 59 & 438.0 & \multirow{2}{*}{0.48 (0.33 to 0.69$)$} \\
\hline Vitamin A & 141.1 & 30 & 208.2 & \\
\hline \multicolumn{5}{|l|}{$>2000-2499 \mathrm{~g}:$} \\
\hline Placebo & 711.1 & 58 & 81.6 & \multirow{2}{*}{0.76 (0.52 to 1.10$)$} \\
\hline Vitamin A & 698.3 & 43 & 61.6 & \\
\hline \multicolumn{5}{|l|}{$2500-2749 \mathrm{~g}:$} \\
\hline Placebo & 703.5 & 24 & 34.1 & \multirow{2}{*}{1.39 (0.84 to 2.33 ) } \\
\hline Vitamin A & 714.5 & 34 & 47.6 & \\
\hline \multicolumn{5}{|l|}{ 2750-2999 g: } \\
\hline Placebo & 580.4 & 28 & 48.2 & \multirow{2}{*}{0.97 (0.58 to 1.62 ) } \\
\hline Vitamin A & 578.7 & 27 & 46.7 & \\
\hline \multicolumn{5}{|l|}{$\geq 3000 \mathrm{~g}:$} \\
\hline Placebo & 589.3 & 19 & 32.2 & \multirow{2}{*}{0.64 (0.32 to 1.31$)$} \\
\hline Vitamin A & 577.5 & 12 & 20.8 & \\
\hline \multicolumn{5}{|l|}{ <2500 g: } \\
\hline Placebo & 845.8 & 117 & 138.3 & \multirow{2}{*}{0.63 (0.48 to 0.83 ) } \\
\hline Vitamin A & 842.4 & 73 & 86.7 & \\
\hline \multicolumn{5}{|l|}{$\geq 2500 \mathrm{~g}:$} \\
\hline Placebo & 1873.2 & 71 & 37.9 & \multirow{2}{*}{1.03 (0.75 to 1.42$)$} \\
\hline Vitamin A & 1870.7 & 73 & 39.0 & \\
\hline
\end{tabular}

Hopkins University) and the Office of Health and Nutrition (US Agency for International Development, Washington DC), the Bill and Melinda Gates Foundation (Seattle, Washington), and Task Force Sight and Life (Basel, Switzerland). These financial supporters had no role in the design, conduct, analysis, or reporting of this study.

Competing interests: JMT, JK, and CC have received support from the Sight and Life Institute, Center for Human Nutrition, Johns Hopkins Bloomberg School of Public Health. The institute was established with a gift from Task Force Sight and Life, Roche. 
Ethical approval: This study was approved by the Aravind Eye and Children's Hospitals, the Department of Health, Tamil Nadu state government, and the Committee on Human Research of the Johns Hopkins Bloomberg School of Public Health.

1 Sommer A, West KP Jr. Vitamin A deficiency:health, survival, and vision. New York, Oxford University Press, 1996.

2 Sommer A, Tarwotjo I, Djunaedi E, West KP Jr, Loeden AA, Tilden R, et al. Impact of vitamin A supplementation on childhood mortality. A randomized controlled community trial. Lancet 1986:1:1169-73.

3 Rahmathullah L, Underwood BA, Thulasiraj RD, Milton RC, Ramaswamy $\mathrm{K}$, Rahmathullah R, et al. Reduced mortality among children in southern India receiving a small weekly dose of vitamin A. $N$ Engl $J$ Med 1990;33:929-35

4 Daulaire NMP, Starbuck ES, Houston RM, Church MS, Stukel TA, Pandey MR. Childhood mortality after a high dose of vitamin A in a high risk population. BMJ 1992:304:207-10.

5 West KP Jr, Pokhrel RP, Katz J, LeClerq SC, Khatry SK, Shrestha SR, et al. Efficacy of vitamin A in reducing pre-school child mortality in Nepal. Lancet 1991:338:67-71.

6 Muhilal, Permeisih D, Idjradinata YR, Muherdiyantiningsih, Karyadi D Vitamin A fortified monosodium glutamate and health, growth, and survival of children: a controlled field trial. Am J Clin Nutr 1988;48:1271-6.

7 Ghana VAST Study Team. Vitamin A supplementation in northern Ghana: effects on clinic attendances, hospital admissions, and child mortality. Lancet 1993;342:7-12.

8 Beaton GH, Martorell R, Aronson KJ, Edmonston B, McCabe G, Ross AC, et al. Effectiveness of vitamin A supplementation in the control of young child morbidity and mortality in developing countries. State of the art series, mutrition poligy discussion paper No 13. Geneva: Administative Com Nations, Dec 1993 .

9 Shenai JP, Chytil F, Jhaveri A, Stahlman MT. Plasma vitamin A and retinol-binding protein in premature and term neonates. I Pediatr 1981:99:302-5.

10 Olson JA. Liver vitamin A reserves of neonates, preschool children and adults dying of various causes in Salvador, Brazil. Arch Latinoam Nut 1979;29:521-45

11 Olson JA, Gunning DB, Tilton RA. Liver concentrations of vitamin A and carotenoids as a function of age and other parameters of American children who died of various causes. Am J Clin Nutr 1984;39:903-10.
12 Wallingford JC, Underwood BA. Vitamin A deficiency in pregnancy, lactation and the nursing child. In: Bauernfeind JC, ed. Vitamin A deficiency and its control. Orlando, FL; Academic Press, 1986:101-52.

13 Stoltzfus RJ, Hakimi M, Miller KW, Rasmussen KM, Dawiesah S, Habich $\mathrm{J}-\mathrm{P}$, et al. High dose vitamin A supplementation of breast-feeding Indonesian mothers: effects on the vitamin A status of mother and infant J Nutr 1993;123:666-75.

14 Rice AL, Stoltzfus RJ, de Francisco A, Chakraborty J, Kjolhede CL, Wahed MA. Maternal vitamin A or $\beta$-carotene supplementation in lactating Bangladeshi women benefits mothers and infants but does not prevent subclinical deficiency. J Nutr 1999;129:356-65.

15 West KP Jr, Katz J, Shrestha SR, LeClerq SC, Khatry SK, Pradhan EK, et al. Mortality of infants under six months of age supplemented with vitamin A: a randomized, double-masked trial in Nepal. Am J Clin Nutr 1995;62:143-8.

16 WHO/CHD Immunization-Linked Vitamin A Supplementation Study Group. Randomized trial to assess benefits and safety of vitamin A supplementation linked to immunization in early infancy. Lancet 1998;353:1257-63

17 Katz J, West KP Jr, Khatry SK, Pradhan EK, LeClerq SC, Christian P, et al. Maternal low-dose vitamin A or beta carotene supplementation has no effect on fetal loss and early infant mortality: a randomized cluster trial in Nepal. Am J Clin Nutr 2000;71:1570-6.

18 Humphrey JH, Agoestina T, Wu L, Usman A, Nurachim M, Subardja D, et al. Impact of neonatal vitamin A supplementation on infant morbidity and mortality. J Pediatr 1996;128:489-96.

19 Shenai JP, Kennedy KA, Chytil F, Stahlman MT. Clinical trial of vitamin A supplementation in infants susceptible to bronchopulmonary dysplasia. Pediatr 1987:111:269-77.

20 Semba RD, Muhilal, Ward BJ, Griffin DE, Scott AL, Natadisastra G, et al. Abnormal T-cell subset proportions in vitamin A deficient children. Lancet 1993;341:5-8.

21 Pasatiempo AMG, Kinshita M, Taylor CE, Ross AC. Antibody response in vitamin A depleted rats is impaired after immunization with bacterial polysaccharide or protein antigens. Fed Am Soc Exp Biol J 1990;4:2518-27.

22 Ross CA. The relationship between immunocompetence and vitamin $A$ status. In: Sommer A, West KP Jr, eds. Vitamin A deficiency: health, survival and vision. New York, Oxford University Press, 1996:251-73.

23 DeLuca LM. Retinoids and their receptors in differentiation, embryogenesis, and neoplasia. Fed Am Soc Exp Biol J 1991;5:2924-33.

24 Cantorna MT, Nashold FE, Hayes CE. In vitamin A deficiency multiple mechanisms establish a regulatory $\mathrm{T}$ helper cell imbalance with exces Th 1 and insufficient Th 2 function.J Immunol 1994;152:1515-22. (Accepted 16 April 2003) 